\title{
Adaptações de Sonho de uma noite de verão para o público infantojuvenil ${ }^{1}$
}

\author{
Isadora Schwenck Corrêa de Brito e Marcia A. P. Martins
}

Este artigo tem como proposta analisar três reescritas em português do Brasil da comédia shakespeariana A Midsummer Night's Dream (Sonho de uma noite de verão): a adaptação realizada por Ana Maria Machado, publicada em 1997 pela Scipione; a adaptação em formato de narrativa ilustrada Turma da Mônica Jovem, de Maurício de Sousa e Fernando Nuno, publicada em 2015 pela editora Girassol; e o mangá Sonho de uma noite de verão da série Mangá Shakespeare, publicada no Brasil pela Galera Record em 2014, com ilustrações de Kate Brown e tradução de Alexei Bueno. A partir desse corpus, busca-se investigar de que maneira as adaptações são realizadas, isto é, os processos multimodais adotados nas reescritas examinadas e em que medida as principais características da obra shakespeariana são mantidas e/ou alteradas, nos quesitos tema, trama, perfil dos personagens e linguagem.

O conceito de adaptação utilizado é o de Julie Sanders (2006, p. 18-19), que considera adaptação como: (a) uma prática transposicional, em que um gênero textual é transformado em outra modalidade, o que pode envolver um processo amplificatório que inclui adição, expansão, acréscimo e interpolação; (b) uma prática que com frequência implica no fornecimento de comentários

\footnotetext{
${ }^{1} \mathrm{O}$ presente trabalho decorre de uma pesquisa realizada em 2017 financiada pelo CNPq no seu Programa de Iniciação Científica, no âmbito do projeto "Adaptações de obras clássicas para o público infantojuvenil", desenvolvido por Marcia A. P. Martins (orientadora) e Isadora Schwenck Corrêa de Brito (bolsista de IC e então aluna do Bacharelado em Letras - Tradutor da PUC-Rio). Parte dos resultados foram apresentados no XXV Seminário de Iniciação Científica e Tecnológica da PUC-Rio, realizado nos dias 29 de agosto a 1 de setembro de 2017.
} 
sobre o texto-fonte; (c) uma tentativa de tornar os textos "relevantes" ou facilmente compreensíveis através da sua atualização. Além disso, outro conceito utilizado é a definição proposta pelo dicionário Gramática Houaiss da Lingua Portuguesa (Azeredo, 2009), segundo a qual: “[t]radução e paráfrase mesclam-se no gênero 'tradução adaptada', comum quando se trata de traduzir obras literárias muito extensas para o público infantil ou infantojuvenil"' (p. 99).

A escolha de obras infantojuvenis como corpus de análise justifica-se pela percepção de que os clássicos são constantemente indicados pelas instituições de ensino e pela rede familiar das crianças e dos jovens. Ao distribuir as adaptações dos clássicos para esse público, espera-se que eles sejam introduzidos na prática da leitura. $O$ governo brasileiro oferece programas que visam estimular as crianças e os jovens a ler, como o PNBE (Programa Nacional Biblioteca da Escola), que distribui obras de apoio ao ensino de educação básica em escolas da rede pública. Assim, observa-se uma preocupação por parte da sociedade em desenvolver a habilidade leitora desde cedo. Porém, em termos mais específicos, quais são os benefícios de se ler os clássicos desde cedo?

Ler os clássicos desde a infância e adolescência demonstra ser extremamente relevante para o desenvolvimento do hábito da leitura, que propicia a ampliação do conhecimento de mundo e da capacidade de refletir sobre pessoas, objetos e situações. Ana Maria Machado (2002), no livro Como e Por Que Ler Os Clássicos Universais Desde Cedo, pontua a importância do primeiro contato de um leitor com uma obra clássica através de uma adaptação:

Também não é necessário que essa primeira leitura seja um mergulho nos textos originais. Talvez seja até desejável que não o seja, dependendo da idade e da maturidade do leitor. Mas creio que o que se deve procurar propiciar é a oportunidade de um primeiro encontro. $\mathrm{Na}$ esperança de que possa ser sedutor, atraente, tentador. E que possa redundar na construção de uma lembrança (mesmo vaga) que fique por toda a vida. Mais ainda: na torcida para que, dessa forma, possa equivaler a um convite para a posterior 
exploração de um território muito rico, já então na fase das leituras por conta própria. (MACHADO, 2002, p. 12-13)

Dessa maneira, Machado ressalta a necessidade de o primeiro contato de um leitor com o processo de leitura de um clássico ser envolvente, até para que, posteriormente, ele se torne um leitor ávido. A autora enfatiza que esse contato pode - e até deve - ser feito através de adaptações, porque essas são obras compatíveis com a maturidade mental e emocional desse leitor em especial. Ainda sobre essa questão, Formiga (2009), em sua tese de doutorado Adaptação de clássicos literários: uma história de leitura no Brasil, afirma: "Na tentativa de minimizar uma possível resistência dos alunos em relação aos clássicos, o primeiro contato poderia ser perfeitamente estabelecido por uma adaptação" (FORMIGA, 2009, p.137).

Assim, as adaptações dos clássicos configuram-se uma ferramenta importante não só para introduzir as crianças e os jovens ao hábito da leitura, mas também para estabelecer um encontro do público-leitor com as obras que fazem parte do cânone universal. Muitas dessas obras lançam luz sobre aspectos da alma humana e discutem questões de identidade, de relacionamentos, de política e de sociedade, como é o caso da comédia shakespeariana A Midsummer Night's Dream.

\section{A Midsummer Night's Dream}

A Midsummer Night's Dream (em português, comumente intitulada Sonho de uma noite verão, como passaremos a nos referir à peça) foi escrita por Shakespeare em 1595-96 para um casamento aristocrático, segundo se acredita. O momento em que foi produzida difere do momento cronológico da sua ação; a peça faz referências à cultura greco-latina, que é bem distante do contexto da Inglaterra do século XVI. A trama gira em torno do casamento entre a rainha amazona Hipólita e o duque de Atenas, Teseu, que precisa julgar um conflito familiar. Egeu deseja casar sua filha Hérmia com Demétrio, porém ela se recusa, dizendo amar Lisandro. Hérmia decide fugir para a floresta com o seu 
amado, mesmo sabendo das consequências de sua desobediência. Demétrio vai atrás de Hérmia, e é, por sua vez, seguido por Helena, sua admiradora. Ao mesmo tempo, na floresta, Titânia e Oberon, respectivamente a rainha das fadas e o rei dos elfos, disputam a guarda de um menino. As duas tramas, então, acabam se sobrepondo quando Oberon decide ajudar Helena a conseguir o amor daquele por quem ela é apaixonada. Entrelaçando-se com essas duas há, ainda, a subtrama dos artesãos, que, em grupo, preparam na floresta o presente de casamento para os noivos Teseu e Hipólita: uma peça teatral de criação própria.

A peça tem nove cenas distribuídas em seus cinco atos, e é escrita na tradicional forma shakespeariana que combina prosa, versos brancos e versos rimados. Nota-se que os discursos das personagens aparecem na forma de verso quando estão relacionados ao amor e à magia. Quando uma personagem se dirige a quem ela ama - mesmo que esteja sentindo raiva em relação à pessoa -, seu discurso vem sob a forma de dísticos rimados. Assim, o esquema rímico predominante é $a a b b c c$, como ilustra a fala de Hérmia reproduzida a seguir, quando a jovem está na floresta e acorda de um pesadelo, pedindo para que Lisandro a ajude:

Help me, Lysander, help me; do thy best

To pluck this crawling serpent from my breast. (a)

Ay me, for pity! What a dream was here!

Lysander, look how I do quake for fear.

Methought a serpent eat my heart away

And you sat smiling at his cruel prey.

(AMND, II.ii.145-150)

Para a análise das adaptações da obra, é relevante perceber tanto os aspectos rímicos e métricos quanto os semânticos, para observar de que modo eles estão presentes na reescrita; em outras palavras, há que verificar se a versificação foi alterada de modo a manter a rima ou não. Em relação à 
história, é preciso identificar de que forma a trama e a subtrama foram transportadas para a adaptação, de que forma foram modificadas ou reduzidas. Se forem reduzidas, é necessário perceber o que foi cortado e o que não foi e, em relação aos personagens, quais foram mantidos e quais foram eliminados.

Além desses fatores, existe uma série de outros aspectos que precisam ser levados em consideração para a leitura crítica de uma adaptação, dentre os quais: quem é a pessoa a adaptar a obra, qual o público-alvo da adaptação e, por conseguinte, qual é a proposta da publicação. Serão, portanto, esses os fatores a serem analisados nas três obras selecionadas, a começar pela adaptação de Ana Maria Machado.

\section{Sonho de uma noite de verão, adaptação de Ana Maria Machado}

Ana Maria Machado é uma escritora renomada de livros infantojuvenis e adultos, obtendo prêmios tanto a nível nacional, como o Jabuti, quanto a nível internacional, como o Hans Christian Andersen. É também adaptadora de obras como O Jardim Secreto, de Frances Hodgson Burnett, As Aventuras do Tom Sawyer, de Mark Twain, e As Viagens de Marco Polo, de Marco Polo². Machado tem uma carreira de peso para a cultura-alvo, o que lança luz para o leitor da importância do processo de escrita criativa envolvido na adaptação da obra em questão.

Colocar um nome de destaque para adaptar uma obra importante no cânone shakespeariano demonstra a preocupação da editora em oferecer um produto de qualidade para o público infantojuvenil brasileiro. É através de coleções como a Reencontro, da editora Scipione, que jovens leitores brasileiros podem não apenas ter proximidade com o bardo, como também alcançar uma compreensão maior do que se trata a obra, já que um roteiro de trabalho é anexado ao livro. Desse modo, existe um interesse da editora em preparar uma

\footnotetext{
${ }^{2}$ Biografia disponível em http://www.anamariamachado.com/biografia. Acesso em 24 jan.17.
} 
edição que possa sustentar debates, tanto na escola, quanto em casa, sobre literatura.

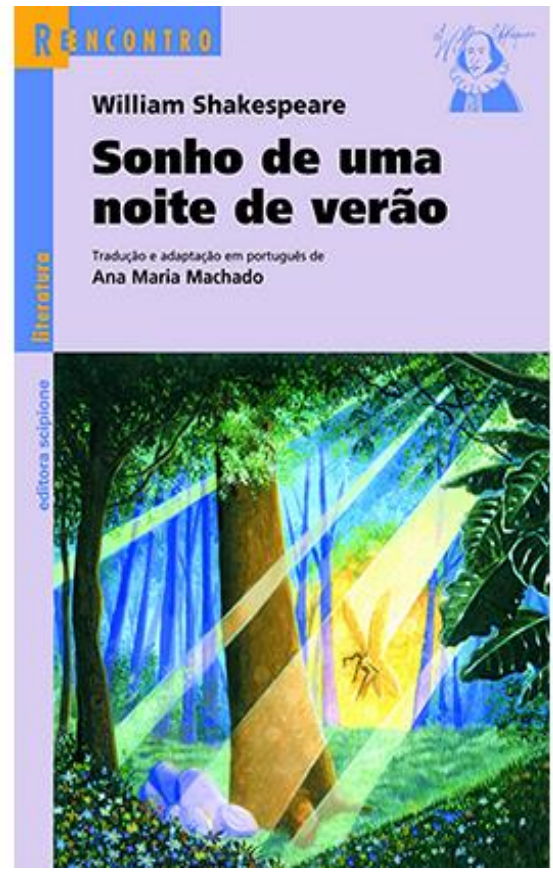

Figura 1 - Capa da adaptação de Sonho de uma noite de verão, de Ana Maria Machado (Fonte: edição impressa).

Fornecer ao público uma adaptação com características educativas e didáticas - incluindo ilustrações, que proporcionam a visualização do que acontece na história, e também um roteiro de trabalho, como já mencionado tem por propósito fazer com que a obra seja conhecida na cultura-alvo e bem acolhida entre o grupo de leitores a que se destina. Assim, a editora preocupou-se em tornar o texto-fonte aplicável à cultura-alvo e ao públicoalvo, leitores infantojuvenis. Machado escolheu transformar o gênero peça teatral em gênero narrativo, apresentando e descrevendo as personagens de modo a dinamizar o entendimento da função de cada uma delas por parte do referido público. 


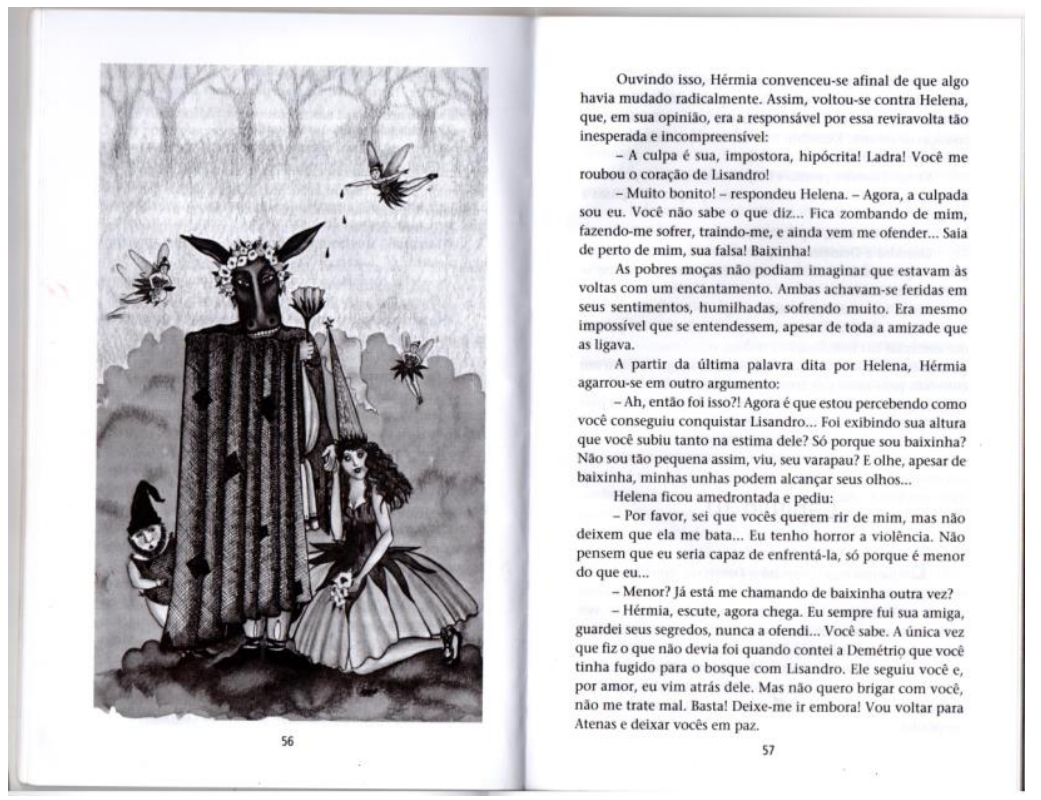

Figura 2 - Interior da adaptação de Sonho de uma noite de verão, de Ana Maria Machado (Fonte: edição impressa).

A autora forneceu soluções interessantes para os versos da peça original. Por exemplo, quando o elfo Puck vai pingar a poção da flor nos olhos de Lisandro, no original, ele diz:

$[\ldots]$

Churl, upon thy eyes I throw

All the power this charm doth owe:

When you wak'st let love forbid

Sleep this seat on thy eyelid.

So awake when I am gone;

For I must now to Oberon.

(AMND, II.ii.78-83) 
A adaptação reduz bastante a fala de Puck - que no texto em inglês é composta de 18 versos e, na adaptação, de cinco. A participação de Puck fica, então, concentrada no ato de colocar o líquido mágico nos olhos de Lisandro:

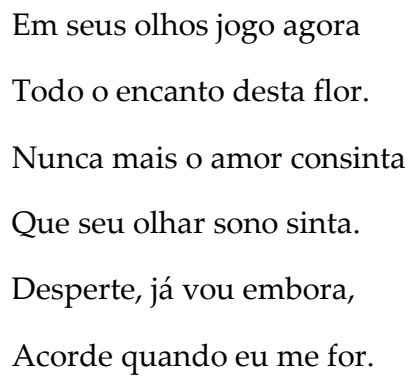

(SHAKESPEARE, 1997, p.35)

Machado encontrou uma maneira criativa de manter a ideia do original e forneceu uma boa solução para as rimas soarem naturais na língua-meta: se, no original, os versos rimam dois a dois (seguindo o padrão $a a b b c c$ ), na adaptação, o primeiro rima com o quinto, o segundo com o sexto e o terceiro com o quarto $(a b c c a b)$. Aparentemente, ela optou por mexer com a estrutura dos versos para manter o sentido e flexibilizar o ato de encontrar rimas na língua-meta.

Em relação ao desenrolar da história na adaptação, é perceptível que Ana Maria Machado reduziu bastante a subtrama dos artesãos. Se partes importantes da peça original dão enfoque à relação dos artesãos com a peça que preparam, Píramo e Tisbe, o mesmo destaque não é dado na adaptação para o português. Os ensaios, no original, ocorrem na cena ii do Ato I e na cena i do Ato III; a encenação da peça para os noivos acontece no Ato V. Assim, na adaptação, a cena ii do Ato I e a cena i do Ato III foram bastante enxugadas na forma de prosa, sendo o cerne dos diálogos ocorridos durante os ensaios de Píramo e Tisbe transferido para descrições narrativas. Além disso, é possível perceber que a encenação da peça Píramo e Tisbe também foi bastante reduzida. 
Deu-se mais relevo à trama principal, enquanto a subtrama foi bem mais condensada.

Outro aspecto que merece ser mencionado é que a adaptadora manteve as características das personagens muito nítidas, deixando isso visível em seus discursos. Um exemplo disso é a personagem Hérmia, uma jovem que está iniciando as suas descobertas relativas à sexualidade e à autoimagem. $\mathrm{O}$ contraste físico entre Hérmia e Helena é evidente: enquanto a primeira é baixa e tem cabelos escuros, a segunda é alta e tem cabelos loiros. Os traços físicos de Helena são mais condizentes com o padrão de beleza da época do que os de sua amiga.

Essa percepção vai ter um papel importante para o momento em que Hérmia nota que Helena, da noite para o dia, conquista o amor dos seus dois admiradores. A personagem fica furiosa, deixando os ciúmes transparecerem em seu discurso. Ana Maria Machado reproduziu esses traços muito bem, explicitando-os na fala de Hérmia, como é perceptível no seguinte trecho:

Ouvindo isso, Hérmia convenceu-se afinal de que algo havia mudado radicalmente. Assim, voltou-se contra Helena, que, em sua opinião, era a responsável por essa reviravolta tão inesperada e incompreensível:

- A culpa é sua, impostora, hipócrita! Ladra! Você me roubou o coração de Lisandro!

(SHAKESPEARE, 1997, p.47)

Hérmia usa palavras como "hipócrita" e "ladra" para se referir a Helena. A escolha desses adjetivos reflete a revolta da personagem ao perceber que Lisandro está apaixonado por sua amiga. É possível que essa revolta esteja relacionada à insegurança que Hérmia traz consigo de que Lisandro a qualquer momento pode se apaixonar por uma mulher considerada mais bela do que ela. Por isso, ela se volta contra Helena, acusando-a de ter "roubado o coração de Lisandro", responsabilizando-a por sua frustração amorosa.

Por todos os fatores mencionados, essa adaptação de Sonho de uma noite de verão parece cumprir o seu papel de introduzir os jovens leitores no universo 
shakespeariano, instigando a capacidade de interpretação de texto e fazendo com que o público-alvo se familiarize com autores que fazem parte do cânone universal. O olhar de Ana Maria Machado sobre a obra shakespeariana é o de uma escritora experiente na literatura infantojuvenil brasileira, capaz de fornecer soluções tradutórias inteligentes, abrindo portas para atrair $\mathrm{o}$ interesse do público pela obra em si e pela leitura em geral.

\section{Sonho de uma noite de verão, Turma da Mônica Jovem}

Turma da Mônica é uma história em quadrinhos tradicional na cultura brasileira, quando se fala em literatura infantil. Produzida há mais de quatro décadas, é considerada referência para alfabetização de crianças. No entanto, Maurício de Sousa não se restringiu ao público infantil; em 2008, foi publicada a primeira revista da Turma da Mônica Jovem (TMJ). Como o próprio nome sugere, nessa nova revista, Cascão, Magali, Cebolinha e Mônica, além de outros personagens, assumem a forma adolescente para tratar de questões próprias desse universo, como desilusões amorosas, aceitação do próprio corpo e preocupações com a escola. Além disso, a revista segue em parte o formato de mangá japonês ${ }^{3}$, que é algo que vem conquistando cada vez mais o público adolescente no Brasil.

Em 2015, a editora Maurício de Sousa, em parceria com a editora Girassol, lançou adaptações das obras A Ilha do Tesouro, de Robert Louis Stevenson, e Sonho de uma noite de verão, de William Shakespeare, nas quais as personagens de Turma da Mônica Jovem interpretam as personagens das histórias. Na adaptação da obra shakespeariana, Teseu é interpretado por Franjinha; Hipólita, por Marina; Egeu, por Titi; o papel de Titânia ficou a cargo de Carminha Frufru; Do Contra é Oberon; Dudu representa Puck e Jeremias, Pedro Marmelo; e as personagens Helena, Demétrio, Hérmia e Lisandro são

\footnotetext{
${ }^{3} \mathrm{O}$ mangá é um estilo de história em quadrinhos geralmente lido da direita para esquerda e de trás para frente na qual as personagens têm olhos grandes e expressivos, além de seguir uma cartela de cores de tons de preto e cinza. Maurício de Sousa optou por manter a leitura ocidentalizada, ou seja, da esquerda para a direita e começando pela frente. Ademais, pode-se dizer que metáforas visuais ganham destaque no mangá para expressar as reações das personagens.
} 
encenadas, respectivamente, por Magali, Cascão, Mônica e Cebola. A tradução e a adaptação da obra foram realizadas por Fernando Nuno.

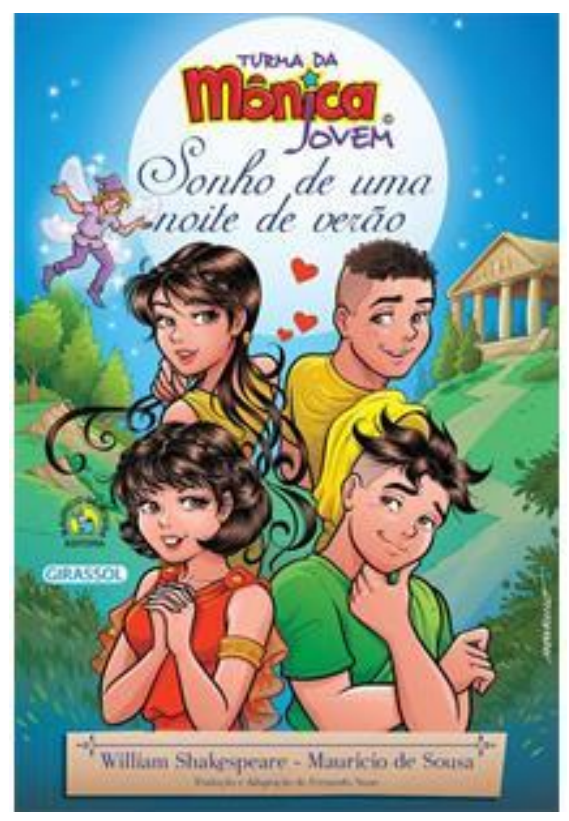

Figura 3 - Capa do mangá da Turma da Mônica Jovem (Fonte: edição impressa).

Nuno é formado em Jornalismo e Letras, além de ter cursado história da arte na Itália. Atualmente, está envolvido em projetos de produção textual, editoração e composição musical. Organizou a Coleção Shakespeare pela editora Objetiva, que contempla os títulos Romeu e Julieta, Sonho de uma noite de verão, Hamlet e Macbeth, e recebeu o título de "Altamente recomendável" pela Fundação Nacional do Livro Infantil e Juvenil (FNLIJ) ${ }^{4}$. As credenciais do adaptador evidenciam o cuidado da editora em oferecer ao público jovem um produto cujo texto e ilustrações foram realizados por pessoas experientes na área da literatura infantojuvenil.

\footnotetext{
${ }^{4}$ Informações disponíveis em: $\quad$ www.companhiadasletras.com.br/autor.php?codigo=01385, www.editoradcl.com.br/Pessoa/299/fernando-nuno e www.saidadeemergencia.com/autor/fernando-nuno/. Acesso em 28 abr. 2017.
} 
Em relação ao texto da obra, pode-se perceber que segue o formato textual híbrido. Existem indicações referentes ao texto dramático - como Primeiro Ato, Segundo Ato e assim por diante -, mas ao mesmo tempo, o corpo do texto é narrativo. As falas das personagens são precedidas por uma descrição da cena pelo narrador da história. Se, na obra original, há a rubrica da cena para contextualizá-la, o que é típico do texto dramático, na adaptação da Turma da Mônica Jovem isso vem pela narração. Isso é perceptível logo na primeira cena do primeiro ato; no original, há a rubrica para demarcar a ação (Enter THESEUS, HIPPOLYTA, PHILOSTRATE and ATTENDANTS) e a exposição do acontecimento do casamento entre Hipólita e Teseu vem através da fala deles:

Theseus

Now, fair Hippolyta, our nuptial hour

Draws on apace; four happy days bring in

Another moon; but $\mathrm{O}$, methinks, how slow

This old moon wanes! She lingers my desires,

Like to a step-dame or a dowager,

Long withering out a man's revenue.

Hippolyta

Four days will quickly steep themselves in night;

Four nights will quickly dream away the time;

And then the moon, like to a silver bow

New-bent in heaven, shall behold the night

Of our solemnities.

(AMND, I. i. 1-15)

Teseu e Hipólita fazem referência ao casamento deles, constatam que o evento está chegando e revelam certa ansiedade para que ele ocorra. É importante perceber a construção discursiva do trecho em questão, permeado por rimas internas e figuras de linguagem, como a comparação. Na segunda 
linha, por exemplo, a palavra "apace" rima com a palavra "days", e, na terceira linha, "O" rima com a palavra "slow"; na sétima linha, "night" rima com "time". Com relação a figuras de linguagem, fica claro que Shakespeare faz uso da comparação. Ele usa elementos da natureza - no caso, a lua - não só para demarcar a passagem do tempo como também para criar uma relação de proximidade com os sentimentos da personagem Teseu. Quanto mais tempo a lua demora a mudar de fase, isto é, quanto mais os dias custam a passar, mais intensa a vontade de Teseu em estar com Hipólita.

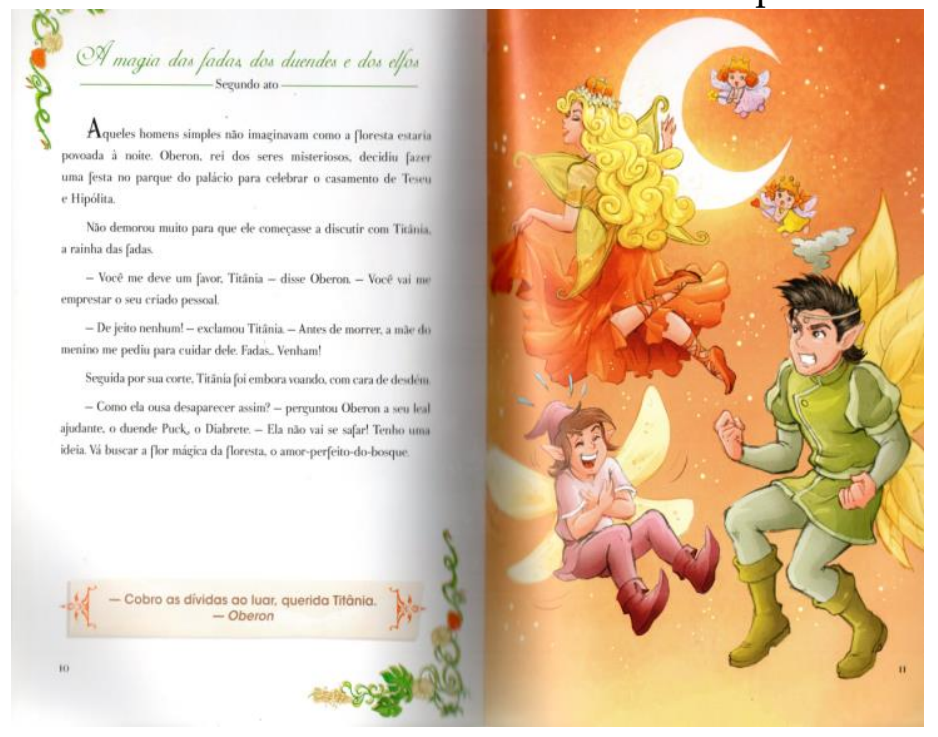

Figura 4 - Página interna do mangá Turma da Mônica Jovem (Fonte: edição impressa).

Esses traços do original, tais como as rimas, as rubricas e as figuras de linguagem, não se fazem presentes na adaptação realizada por Nuno. O que se percebe é que há uma descrição narrativa em terceira pessoa para situar o leitor do que está acontecendo: "Atenas estava em clima de festa. Afinal, Teseu, duque de Atenas, iria se casar com Hipólita, rainha das Amazonas em poucos dias" (SHAKESPEARE, 2015, p.4).

A narração descritiva em questão é bastante sintética, sendo possível dizer que a questão da ansiedade de Teseu em casar-se com Hérmia, presente no original, está ausente da tradução, bem como as comparações. A 
criação/construção do cenário de uma Atenas animada para o casamento é mais objetiva nessa adaptação.

Ainda em relação às questões rímicas em Turma da Mônica Jovem, observa-se que não há passagens rimadas nessa adaptação. Na reescrita de Nuno, a linguagem da obra se mostra mais próxima do público-leitor, com muitas expressões idiomáticas, e apresenta naturalidade na fala oral. Isso é perceptível, por exemplo, no segundo ato, quando Helena persegue Demétrio pelo bosque e ele se irrita com ela:

Pobre Helena! Amava Demétrio, mesmo que ele a tratasse mal.

- Mas eu amo você, Demétrio! - suspirou ela.

- Deixe-me em paz! - gritou ele, saindo de perto de Helena.

(SHAKESPEARE, 2015, p.12).

A expressão "deixar em paz" é bastante comum no contexto do português brasileiro, e faz um contraste com uma solução mais formal para traduzir essa fala de Demétrio, apresentada ao pé da página: “Não lhe tenho amor, por isso não me persiga". Essa estratégia é empregada ao longo da peça: todas as páginas de texto trazem em destaque, na parte inferior, uma tradução mais formal para a fala de algum personagem ali reproduzida. É interessante mencionar que colocar dois estilos diferentes de tradução - mesmo que seja para um número reduzido de falas - é bastante educativo, pois faz com que os leitores, aos poucos, sejam introduzidos a leituras mais complexas.

Além disso, outro aspecto importante é a redução da subtrama. Foi dada pouca ênfase ao ensaio dos artesãos para a apresentação no casamento de Teseu e Hipólita. Exclusivamente a eles, foram destinadas somente três cenas (SHAKESPEARE, 2015, p. 8, 20 e 22), ficando o foco central da adaptação voltado para a trama principal.

No que diz respeito às ilustrações, o formato da adaptação de Sonho de uma noite de verão da Turma da Mônica Jovem (TMJ) também é bastante híbrido. Ao mesmo tempo em que traços do estilo japonês são visíveis no trabalho de 
Maurício de Sousa, como os expressivos olhos grandes, por exemplo, outros aspectos típicos do mangá estão ausentes da revista. Geralmente, as ilustrações de um mangá obedecem à escala de preto e cinza, o que não ocorre na adaptação shakespeariana. $\mathrm{O}$ uso das cores na adaptação ajuda a atribuir ludicidade à obra, que tem muitas referências a elementos míticos como fadas e elfos.

Sobre isso, pode-se dizer que a presença de cores contribui muito para a construção da atmosfera humorística, divertida e mágica dessa comédia shakespeariana. Reconstituir tal atmosfera através de elementos visuais ajuda muito os jovens leitores a compreenderem o enredo da peça, visto que as ilustrações agem em conjunto com o material textual (do lado esquerdo, vem a narrativa; do lado direito, a ilustração). As ilustrações atuam como um elemento cênico, porque retratam o cenário de determinada cena e explicitam a reação das personagens aos acontecimentos narrados através de elementos textuais.

Por todos os motivos aqui expostos, Sonho de uma noite de verão, da TMJ, é uma adaptação que tem características não de história em quadrinhos, mas sim de uma narrativa ilustrada, pois a contextualização das cenas, que no texto dramático se dá através de rubricas, vem através da descrição narrativa, e as falas de cada personagem são transformadas em diálogos. No entanto, a intertextualidade com a peça de Shakespeare fica bem clara, com o artifício de "escalar" as personagens da Turma da Mônica Jovem e fazer as ilustrações funcionarem como recursos cênicos.

\section{Mangá Shakespeare: Sonho de uma noite de verão}

Publicado pela primeira vez na Inglaterra, em 2007, pela SelfMade Hero, um selo da Metro Media Ltda., o mangá A Midsummer Night's Dream apresenta a comédia clássica de William Shakespeare de forma interessante e inovadora. Ilustrado por Kate Brown e adaptado por Richard Appignanesi, a obra conta com ilustrações que unem, ao mesmo tempo, referências da cultura grecolatina, como as togas e os babados, a referências atuais, como gravatas e 
relógios de pulso. Dessa forma, o mangá traz uma feição nova para a literatura do bardo, contribuindo para atrair os jovens contemporâneos, aficionados do estilo de ilustração japonesa, para histórias que fazem parte do cânone ocidental.

A adaptação para mangá de Sonho de uma noite de verão chegou ao Brasil no ano de 2014, pela Galera Record, um selo da editora Record, sendo traduzida por Alexei Bueno ${ }^{5}$. Observam-se aqui, portanto, dois níveis de reescrita: a adaptação (intralingual) da peça para linguagem de mangá, e a posterior tradução da adaptação para o português do Brasil.

Bueno é um escritor premiado, tendo publicado livros como Lucernário (1993), pelo qual recebeu o Prêmio Alphonsus de Guimaraens, e Poemas reunidos (1998), agraciado com o Prêmio Fernando Pessoa. Como tradutor, transpôs para o português poemas de Poe, Mallarmé, Longfellow, dentre outros $^{6}$. Kate Brown, bacharel em Artes Visuais pela Sydney College of the Arts, também tem uma carreira consolidada em sua área ${ }^{7}$.

\footnotetext{
${ }^{5}$ Para mais informações sobre o projeto da SelfMadeHero de adaptação de obras shakespearianas para a linguagem dos mangás e sua tradução para o português em edições da Galera (selo da editora Record), ver MARTINS, M. A. P. The 'Manga Shakespeare' Series Translated into Brazilian Portuguese. New Readings, v.15, p.46-56, 2015 (disponível em http://ojs.cf.ac.uk/index.php/newreadings/article/view/117) e MARTINS, M. A. P. Reescritas de peças de Shakespeare para o público jovem: a série Mangá Shakespeare. Cadernos de Tradução. v.2, p.61-84, 2014 (disponível em https://periodicos.ufsc.br/index.php/traducao/article/view/21757968.2014v2n34p61/28189).

'Informações extraídas de www.antoniomiranda.com.br/poesia_brasis/rio_de_janeiro/alexei_bueno.html. Acesso em 27 mai. 17.

${ }^{7}$ Extraído de https://kateelizabettabrown.wordpress.com/about/. Acesso em 27 mai. 17.
} 


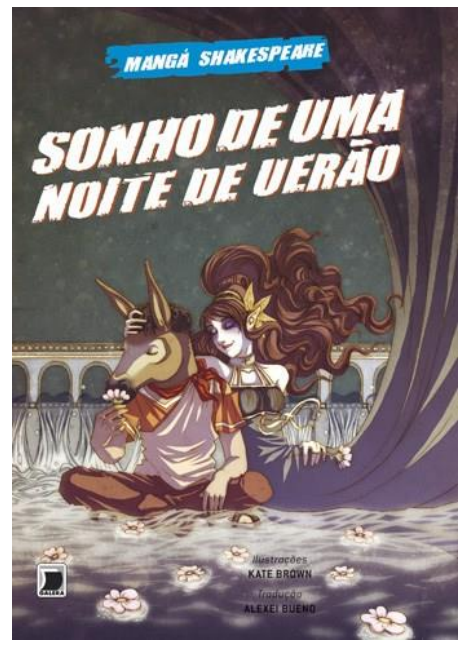

Figura 5 - Capa do mangá Sonho de uma noite de verão (Fonte: edição impressa).

Em Sonho de uma noite de verão, Bueno optou por um texto o mais próximo possível ao original, em termos de estrutura formal. No texto de sua autoria incluído na edição traduzida do mangá, ele afirma que, "[m]esmo nos momentos em que o decassílabo branco inglês [...] foi alterado por cortes, preferimos traduzir todo o trecho em decassílabos brancos portugueses" (BUENO, 2014, p.5).

Ao buscar a manutenção da estrutura formal e das rimas, o texto parece voltar-se mais para jovens que tenham certa maturidade linguística, em termos tanto de vocabulário quanto de familiaridade com o texto poético. A complexidade textual da tradução é inegável; percebe-se o esforço de Bueno para alterar a estrutura sintática da língua, invertendo a sequência natural dos elementos para melhor aproximar o texto à estrutura original. Isso fica claro, por exemplo, na seguinte fala de Demétrio: "Meu coração a Helena retornou e com ela ficará" (SHAKESPEARE, 2014, p. 136).

Esse tipo de estruturação sintática, na qual o complemento vem antes do verbo, é vista mais em obras poéticas ou literárias do que na oralidade do português brasileiro, sobretudo contemporaneamente. Esse aspecto reforça a opção de Bueno de manter o lirismo teatral do texto original e de destacar o 
fato de a obra ter sido escrita há muito tempo, ainda no berço do inglês moderno. Ainda em relação à sintaxe, Bueno diz ter-se beneficiado do fato de a língua portuguesa oferecer muito mais liberdade sintática do que a língua inglesa: "Apesar da forte tendência monossilábica da língua inglesa, e do tamanho médio dos vocábulos maior em nosso idioma, a notável liberdade de sintaxe e a índole sintética do português nos possibilitaram transposições que julgamos muito satisfatórias" (BUENO, 2014, p.5).

Outro aspecto que deve ser destacado é que a trama principal e as subtramas não foram reduzidas. Houve um esforço em se manter a subtrama do ensaio dos artesãos para a peça, presente deles para o casamento de Teseu e Hipólita. Inclusive, seus nomes originais foram mantidos, à exceção de Francisco Flauta, tradução de Bueno para o artesão Flute. Os demais nomes foram traduzidos, com destaque para o das fadas: Semente de Mostarda, Ervilha, Teia e Traça.

Um fato muito curioso é a maneira como Oberon e Titânia são retratados no mangá. Os dois são criaturas místicas e essas características são expressas pela relação luz e sombra presente nas ilustrações. $\mathrm{O}$ único momento em que há cor no mangá é na apresentação das personagens nas primeiras páginas. Embora seja típico dos mangás não ter cores, a estratégia de colocar preto e tons mais escuros quando Oberon e Titânia aparecem enfatiza a atmosfera sombria de ambas as personagens. Além disso, o próprio casal mitológico é representado de maneira mais soturna: Oberon tem chifres de bode e usa vestimentas de cor preta, sendo também escuras as roupas de Titânia. Ademais, a íris dos olhos de ambos é branca, enquanto o restante do olho é preto. Para completar, eles são rodeados por fadas com asas de morcego.

Assim, fica claro que Titânia e Oberon são reis que têm ligação com o sombrio, com o obscuro. Essa interpretação distancia a peça do caráter lúdico que lhe é característico, devido ao uso de magia e da ambientação numa floresta bucólica. A sobriedade da adaptação atribui densidade à obra, mas seu caráter cômico não é anulado. As cenas cômicas têm muita força nessa 
adaptação. Elas são construídas por meio de onomatopeias e metáforas visuais. Esses são elementos narrativos típicos do mangá que funcionam como recursos cênicos para a obra adaptada, visto que estabelecem uma ponte entre as ações realizadas pelas personagens e as emoções que elas sentem.

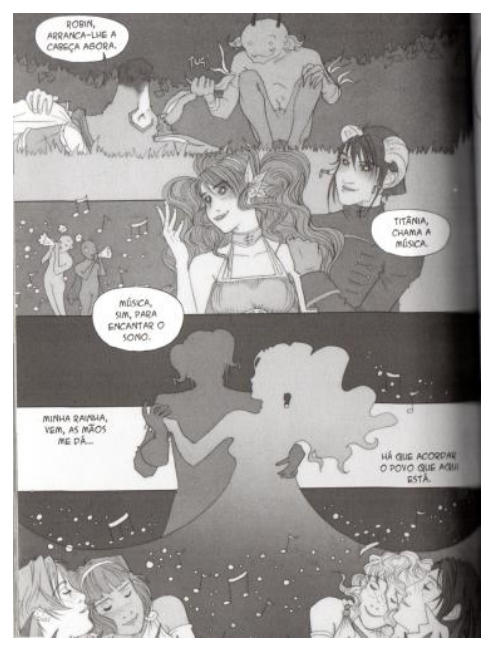

Figura 6 - Oberon e Titânia representados no mangá Sonho de uma noite de verão (Fonte: edição impressa)

No geral, o mangá Sonho de uma noite de verão é muito bem construído. Tem elementos que cativam o público jovem, como o humor, a junção entre o moderno e o antigo e a interatividade que as ilustrações atribuem à obra. Sem dúvida, a série Mangá Shakespeare, tanto na adaptação em inglês como na sua versão traduzida, contribui para que mais e mais leitores sintam-se atraídos pela leitura como um todo, algo que é importante para a sua formação, mas sobretudo pela leitura de clássicos universais, que tocam em questões tão humanas quanto a decepção amorosa, os empecilhos para se viver o amor, e o casamento como instituição.

\section{Considerações finais}


A análise das três reescritas nos permitiu detectar características distintas em cada uma. A adaptação de Ana Maria Machado tem funções pedagógicas claras, viabilizadas por uma série de recursos: um texto explicativo sobre William Shakespeare, uma introdução curta acerca da obra, um texto informativo sobre a adaptadora ao final do livro e a presença de um roteiro de trabalho. Por esses aspectos, pode-se inferir que a adaptação em questão é voltada para a relação aluno-pais-escola, o que não se percebe em Sonho de uma noite de verão, de Maurício de Sousa e Fernando Nuno.

Das três reescritas examinadas, a revista da Turma da Mônica Jovem é a que mais respeitou a atmosfera lúdica e mágica da peça, para a qual muito contribuem as ilustrações em cor. Como foi dito, o texto adaptado é cheio de expressões idiomáticas e coloquiais, quando em comparação ao original. Esses fatores sugerem que o foco principal da adaptação de Maurício de Sousa e Fernando Nuno é a relação leitor-livro. Os recursos adotados contribuem fortemente para o leitor desenvolver uma relação afetiva com a obra, bem como uma independência na leitura. $O$ público-alvo são os leitores préadolescentes, faixa etária em que começam a se constituir como leitores críticos.

Por último, Sonho de uma noite de verão, da série Mangá Shakespeare, tem um público-alvo distinto das adaptações anteriores: os jovens adultos. Isso permite uma complexidade linguística, como a estrutura formal de decassílabos brancos portugueses, e um fôlego de leitura maior - o volume tem 208 páginas. Essa adaptação para o formato de mangá foi a que mais inovou nos quesitos ambientação e estética, visto que trouxe ao leitor elementos futuristas no cenário e no figurino. Além disso, as ilustrações dotaram a história de uma atmosfera mais sombria, acrescentando um clima de suspense à obra shakespeariana.

Finalizando, pode-se afirmar que, embora apresentando características bem diferentes quando contrastadas, as três adaptações têm como denominador comum o cuidado com a linguagem e o material visual. Isso se dá, em grande parte, pela escolha dos tradutores/adaptadores e dos 
ilustradores, pessoas experientes no campo da literatura e das artes visuais. Esse aspecto contribui para que os leitores se sintam cada vez mais atraídos pelo universo da leitura e, naturalmente, pela obra shakespeariana.

\section{Referências}

BUENO, Alexei. Nota do tradutor. In: SHAKESPEARE, William. Sonho de uma noite de verão: mangá Shakespeare. Adaptação de Richard Appignanesi, ilustrações de Kate Brown, tradução de Alexei Bueno. Rio de Janeiro: Galera Record, 2014, p. 5.

FORMIGA, Girlene M. Adaptação de clássicos literários: uma história de leitura no Brasil. 2009. 262 f. Tese (Doutorado em Letras) - Departamento de Letras Clássicas e Vernáculas, Universidade Federal da Paraíba, João Pessoa, 2009.

MACHADO, Ana Maria. Como e por que ler os Clássicos Universais desde cedo. Rio de Janeiro: Objetiva, 2002.

RODRIGUES, Neide Nunes e MELO, Mônica Santos. Do diálogo infantil ao papo dos adolescentes: a organização enunciativa nos quadrinhos de Mauricio de Sousa. Entre Palavras: Revista de Linguística do Departamento de Letras Vernáculas da UFC, v. 3 e n.1. Fortaleza, CE: Universidade Federal do Ceará, 2013, p. 67-85.

TREWIN, J. C. The pocket companion to Shakespeare's plays. London, Auckland, NZ, Melbourne, AUSTRA, Toronto, CAN: Reed International Books Limited, 1994.

SHAKESPEARE, William. A Midsummer Night's Dream. Editado por R.B. Kennedy. London: Collins Classics, 2011.

SHAKESPEARE, William. Sonho de uma noite de verão. Traduzido e adaptado por Ana Maria Machado. São Paulo: Scipione, 1997.

SHAKESPEARE, William. Sonho de uma noite de verão. Ilustrado por Kate Brown, adaptado por Richard Appignanesi e traduzido por Alexei Bueno. Rio de Janeiro: Editora Record Ltda., 2014. 
SHAKESPEARE, William. Sonho de uma noite de verão. Ilustrado por Maurício de Sousa e traduzido e adaptado por Fernando Nuno. Barueri, SP; São Paulo: Girassol e Maurício de Sousa Editora, 2015.

SHAKESPEARE, William. Shakespeare's Comedy of A Midsummer Night's Dream. Ed. Katharine Lee Bates. Boston: Leach, Shewell, \& Sanborn, 1895. Shakespeare Online. 20 Dec. 2009. Disponível em http://www.shakespeareonline.com/plays/midsummer/mdshistory.html Acesso em 05 mar 2018.

\section{Resumo}

A proposta deste trabalho é analisar três reescritas em português do Brasil da comédia shakespeariana A Midsummer Night's Dream (Sonho de uma noite de verão): a adaptação realizada por Ana Maria Machado (Scipione, 1997); a adaptação em formato de narrativa ilustrada Turma da Mônica Jovem, de Maurício de Sousa e Fernando Nuno (Girassol, 2015); e o mangá Sonho de uma noite de verão da série Mangá Shakespeare (Galera Record, 2014), ilustrado por Kate Brown e traduzido por Alexei Bueno. A partir desse corpus, busca-se examinar os processos multimodais adotados nas reescritas e em que medida as principais características da obra shakespeariana são mantidas e/ou alteradas nos quesitos tema, trama, perfil dos personagens e linguagem.

Palavras-chave: William Shakespeare; Sonho de uma noite de verão; adaptação; público infantojuvenil; quadrinhos; mangá.

\footnotetext{
Abstract

The purpose of this article is to analyze three Brazilian Portuguese rewritings of Shakespeare's comedy A Midsummer Night's Dream: an adaptation by Ana Maria Machado (Scipione, 1997); the illustrated narrative Turma da Mônica Jovem, by Maurício de Sousa and Fernando Nuno (Girassol, 2015); and the manga A Midsummer Night's Dream (Sonho de uma noite de verão), belonging to the Manga Shakespeare series (Galera Record, 2014), illustrated by Kate Brown
} 
and translated into Portuguese by Alexei Bueno. The aim is to examine the multimodal processes adopted by the rewritings and to what extent the main features of the play have been retained or altered as regards theme, plot, characters' profile and diction.

Keywords: William Shakespeare; A Midsummer Night's Dream; adaptation; young readers; comics; manga 